\title{
MORFOLOGIA RADICULAR E SUPRIMENTO DE POTÁSSIO ÀS RAÍZES DE MILHETO DE ACORDO COM A DISPONIBILIDADE DE ÁGUA E POTÁSSIO(1)
}

\author{
C. A. ROSOLE ${ }^{(2)}$, G. P. MATEUS(3), L. J . G. GODOY(3), \\ J. C. FELTRAN ${ }^{(3)} \&$ S. R. BRANCALIÃO(3)
}

\begin{abstract}
RESUMO
O milheto (Pennisetum glaucum) é cultivado em épocas com deficiência hídrica, o que pode afetar a absorção de $K$. Este trabalho visou quantificar a importância de potenciais de água do solo $(-0,03 ;-0,05 ;-0,10$ e $-0,50 \mathrm{MPa})$,

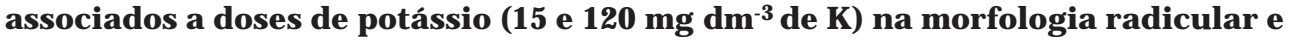
nos processos de transporte de $K$ às raízes de mi lheto. $O$ experimento foi realizado em Botucatu (SP), em casa de vegetação. 0 milheto foi cultivado até 28 dias após a emergência, quando foram avaliados a fitomassa produzida e os teores de $K$, assim como a morfologia radicular. Foi estimada a contribuição do fluxo de massa e da difusão para o transporte de K no solo. Independentemente da dose de potássio e do teor de água no solo, a difusão foi o principal mecanismo de transporte de $\mathrm{K}$ até as raízes do milheto. Houve maior contribuição relativa do fluxo de massa, que correspondeu a $12 \%$ do absorvido, na menor dose de potássio, contra $4 \%$ na maior dose. Não houve efeito da disponi bilidade hídrica nos mecanismos de transporte de $\mathrm{K}$ até as raízes do milheto.
\end{abstract}

Termos de indexação: absorção de K, difusão, fluxo de massa, Pennisetum glaucum.

\section{SUMMARY: ROOT MORPHOLOGY AND POTASSIUM SUPPLY TO PEARL MILLET ROOTS AS AFFECTED BY SOIL WATER AND POTASSIUM CONTENTS}

Pearl millet is usually grown in periods when water is deficient in soil; a fact that possibly affects the K uptake. The experiment in Botucatu, São Paulo State, Brazil, was

\footnotetext{
(1) Trabal ho apresentado no XXVIII Congresso Brasileiro de Ciência do Solo, Londrina (PR). Recebido para publicação em julho de 2002 e aprovado em abril de 2003.

(2) Professor Titular do Departamento de Produção Vegetal, Faculdade de Ciências Agronômicas, Universidade Estadual Paulista FCA/UNESP. Caixa Postal 237, CEP 18603-970 Botucatu (SP). Bolsista do CNPq. E-mail: rosolem@fca.unesp.br.

(3) Pós-Graduando em Agricultura, FCA/UNESP. E-mail: gmateus@fca.unesp.br
} 
conducted to evaluate the effects of soil water content $(-0.03 ;-0.05 ;-0.10$ and $-0.50 \mathrm{MPa})$ associated with $\mathrm{K}$ rates ( 15 and $120 \mathrm{mg} \mathrm{dm}^{-3}$ of $\mathrm{K}$ ) on the $\mathrm{K}$ mass flow and diffusion to pearl millet (Pennisetum glaucum (L.) Leek) roots in greenhouse conditions. In pots with soil from the arable layer of a Red Latosol, pearl millet was grown for 28 days after plant emergence, when the plants were harvested and the shoot and root dry matter, $\mathrm{K}$ contents, as well as theroot mor phol ogy determined. $\mathrm{K}$ mass flow and diffusi on to roots wereestimated. I rrespecti veof soil K level and water content, diffusi on was themain mechanism of K supply to theroots. Therewas a larger relativecontribution of mass flow at the K lowest rate, which amounts to $12 \%$ of the total $\mathrm{K}$ uptake, compared to $4 \%$ at the highest $\mathrm{K}$ rate No effect of the soil water content on the mechanisms of $K$ supply to pearl millet roots was establ ished.

Index terms: diffusion, mass flow, $\mathrm{K}$ uptake, Pennisetum glaucum.

\section{NTRODUÇÃO}

Para que ocorra a absorção dos nutrientes pelas plantas, estes devem estar na solução do sol o eserem transportados até à superfície da raiz ou se encontrarem na rota de crescimento das raízes. Diferentes mecanismos, como fluxo de massa, difusão e intercepção radicular, são responsáveis pel o contato íon-raiz.

Deacordo com Barber (1984), a difusãoécausada pel o movimento ao acaso dos íons em direção à raiz, de acordo com o gradiente de concentração gerado na superfície radicular pelo processo de absorção. Segundo esse autor, a intercepção radicular é considerada muito baixa no suprimento de potássio. Embora haja controvérsia na literatura, Ruiz et al . (1999) recomendam que o mecanismo de interceptação radicular deve ser desconsiderado, pois não há a possibilidade de trocas diretas entre as partículas do solo e as raízes da planta, havendo necessidade de um meio líquido.

O fluxo de massa está associado ao gradiente de potencial hídrico provocado pela absorção de água pelas plantas. Sendo assim, por meio da concentração do íon na sol ução do solo e da taxa de transpiração da planta quantifica-sea proporção transportada por esse mecanismo. A importância relativa do fluxo de massa no suprimento de nutrientes depende da capaci dade do sol o em fornecê-los, além da demanda pela planta, sendo caracterizado pelas diferenças na transpiração, morfologia de raiz e taxa de absorção de potássio, as quais variam com a espécie, idade da planta, atividade da raiz e teor de água do solo (Marschner, 1995).

Geralmente, a difusãoé o mecanismo dominante do transporte de potássio até às raízes das plantas (Marschner, 1995). No entanto, Rosolem et al. (2001) observaram aumento do fluxo de massa no suprimento de $\mathrm{K}$ às raízes de algodão em alta dose de $\mathrm{K}\left(60 \mathrm{mg} \mathrm{dm}^{-3}\right)$, decorrente do maior número de raízes finas e da competição entre as raízes, reduzindo a contribuição da difusão.

O milheto (Pennisetum glaucum (L.) Leek) é comumente cultivado na chamada "safrinha" após a col heita da soja ou milho, aproveitando a umidade residual das últimas chuvas de verão, ou no final de setembro, antecedendo a cultura da soja quando as chuvas são antecipadas (EMBRAPA, 1997). Salton \& Hernani (1994) observaram, em Bonito(MS), que o milheto africano acumula na parte aérea cerca de $377 \mathrm{~kg} \mathrm{ha}^{-1}$ de $\mathrm{K}$, sendo bastante exigente neste nutriente, quando comparado ao milho (196 kg ha-1 de K), como relatado por Büll (1993). Em anos secos, a resposta à aplicação de potássio émai or, indicando estreita correl ação entre o conteúdo de água no solo, a difusão de potássio ea absorção do nutriente pelas plantas (Grimme, 1990).

No sistema de semeadura direta, no qual o milheto vem sendo cultivado, pode ocorrer maior concentração de K disponível nas camadas superficiais dos solos, principal mente nas linhas de semeadura da cultura anterior que, mesmo sem adubação localizada de potássio, apresenta maior concentração deste nutriente próximo às plantas do que nas entrelinhas, o queé explicado pela "lavagem" do K das plantas e descida pelo colmo, concentrandose no solo (Klepker \& Anghinoni, 1995).

A maior parte do $K$ absorvido pelo milheto normalmente entra em contato com a raiz por difusão (Costa et al., 1998) e é observada maior resposta ao nutriente em épocas com baixa disponibilidade hídrica (Grimme, 1990). Tanto a disponibilidade hídrica (Barber, 1984) como a disponibilidade de $\mathrm{K}$ podem influir na morfologia radicular e no bal anço entre os processos de contato K-raiz (Rosolem et al., 2001).

O objetivo deste trabal ho foi quantificar a contribuição dos mecanismos de difusão e fluxo de massa no suprimento de potássio de acordo com níveis de água na cultura do milheto, relacionandoos com possíveis modificações na morfologia do sistema radicular.

\section{MATERIAL E MÉTODOS}

O experimento foi realizado no Departamento de Produção Vegetal da Faculdade de Ciências 
Agronômicas, Botucatu (SP), em condições de casa de vegetação com controle detemperatura, mantida entre 28 e $32{ }^{\circ} \mathrm{C}$. Foi utilizada uma amostra coletada na camada superficial $(0-20 \mathrm{~cm})$ de um Latossolo Vermelho distrófico típico (EMBRAPA, 1999) com $63 \%$ de areia, $4 \%$ de silte e $33 \%$ de argila, passada em peneira de $4 \mathrm{~mm}$, com as seguintes características químicas (Raij \& Quaggio, 1983): $\mathrm{pH}\left(\mathrm{CaCl}_{2}\right)$ de 4,36; $18,4 \mathrm{~g} \mathrm{dm}^{-3}$ de M.O.; $14 \mathrm{mg} \mathrm{dm}^{-3}$ de P (resina); 0,5; 8,0 e $4,0 \mathrm{mmol}_{c} \mathrm{dm}^{-3}$ de $\mathrm{K}+, \mathrm{Ca}^{2+}$ e $\mathrm{Mg}^{2+}$, respectivamente; CTC de 55,4 $\mathrm{mmol}_{\mathrm{c}} \mathrm{dm}^{-3}$ e V de $23 \%$. Uma amostra do solo foi retirada para a determinação da curva de retenção de água, bem como dos teores de água na capacidade de campo e no ponto de murcha permanente, utilizando câmaras depressão deRichards (1949). A amostra foi dividida em subamostras de $4 \mathrm{dm}^{3}$, acondicionadas em sacos plásticos fechados depois de realizada a aplicação decal cário (PRNT 95 \%) para correção da saturação por bases a 60 \% e um litro de água.

Após o período deincubaçãoúmida (20 dias), cada subamostra recebeu $50 \mathrm{mg} \mathrm{dm}^{-3}$ de N e $150 \mathrm{mg} \mathrm{dm}^{-3}$ de $P$, na forma de uréia e superfosfato simples respectivamente. Para a adubação potássica, foram aplicadas duas doses de $\mathrm{K}, 15 \mathrm{e} 120 \mathrm{mg} \mathrm{dm}^{-3}$, na forma de cloreto de potássio. As subamostras de solo foram acondicionadas em vasos de $4 \mathrm{dm}^{3}$ (unidade experimental) distribuídos em quatro blocos casualizados, em esquema fatorial $2 \times 4$ ( 2 doses de $\mathrm{K}$ e 4 teores de água no solo).

Em duas repetições, foram instaladas cápsulas porosas de porcelana, dispostas verticalmente no fundo de cada vaso, para a extração da solução do solo. Para reduzir as perdas por evaporação, foi adicionada uma camada de $10 \mathrm{~mm}$ de areia lavada à superfície do solo em cada vaso.

O teor de água no sol o dos vasos foi corrigido para -0,01 MPa (capacidade de campo), correspondendo a $138 \mathrm{~g} \mathrm{~kg}^{-1}$. Após o período de equilíbrio, foi realizada a semeadura de 12 sementes de milheto, cultivar comum, deixando-se, após a emergência, cinco plantas por vaso.

Os vasos foram pesados diariamente, adicionandose água destilada para retornar o teor de água à capacidade de campo (-0,01 MPa), após atingir valores críticos estabel ecidos para cada tratamento: (1) -0,03 MPa, (2) -0,05 MPa, (3) -0,10 MPa e (4) $-0,50 \mathrm{MPa}$, constituindo quatro tratamentos. Para estimar a evaporação, por diferença, foram utilizados dois vasos sem planta por tratamento.

A extração da solução do solo foi realizada aos 15 DAE (Dias Após a E mergência) eaos 25 DAE com o auxílio de uma bomba de vácuo operando a 138 $\mathrm{KPa}$, extraindo cerca de $70 \mathrm{~mL}$ de solução por vaso, que foram acondicionados em frascos de vidro escuro earmazenados sob refrigeração. As amostras foram filtradas e os teores de K, Ca e Mg na solução do sol o foram determinados por meio de espectrômetro de emissão atômica com plasma de argônio (ThermoSpec ${ }^{\top M} /$ PMT Plasma Spectrometer ICAP).

Vinte e oito dias após a emergência (28 DAE), as plantas foram col hidas e separadas em parte aérea eraízes, descartando-se o solo do vaso. A parte aérea foi lavada, seca em estufa com ventilação forçada a $65{ }^{\circ} \mathrm{C}$ até peso constante, e, em seguida, foi determinada a fitomassa seca. As raízes foram lavadas para retirar as partículas de sol o e pesadas. Foi tomada uma subamostra das raízes (aproximadamente $1 / 8$ do total), a qual foi colocada em frascos com ál cool $50 \%$ armazenados sob refrigeração. O restantedas raízes foi seco em estufa com ventilação forçada a $65^{\circ} \mathrm{C}$ até peso constante, determinando-se, no final, a fitomassa seca das raízes.

As amostras acondicionadas em álcool foram usadas na determinação do comprimento total, área superficial, vol ume total e diâmetro médio por meio da digitalização de imagem utilizando scanner HP Scanjet 4c/T eosoftwareWinRHIZO Reg 3.8b -19931997 (Regent Instruments Inc.). Após essas determinações, as amostras foram secas em estufa e pesadas.

Após a secagem, todo o material vegetal (parte aérea e raízes) foi moído e o $\mathrm{K}$, Ca e $\mathrm{Mg}$ foram extraídos por digestão nitroperclórica. No extrato obtido, foram determinadas as concentrações de K, Ca eMg por espectr ofotometria de absorção atômica (Malavolta et al., 1997).

O fluxo de massa foi determinado aos 15 e $25 \mathrm{DAE}$, multiplicando-se a concentração de $\mathrm{K}$ encontrada na solução do solo pel o volume total de água transpirada, em cada período, ou seja, da emergência até os 15 DAE e dos 15 aos 25 DAE. O $\mathrm{K}$ transportado por difusão foi calculado pela diferença entre o total de K acumulado na planta e - K suprido por fluxo de massa. A intercepção radicular foi desprezada.

Todos os resultados foram submetidos à análise de variância e análise de regressão, sendo comparados a $5 \%$ pelo teste $F$. Nos casos em que nem o teste $F$ nem a regressão foram significativos, foi traçada uma reta, considerando a média dos resultados.

\section{RESULTADOS E DISCUSSÃO}

I ndependentemente da dose de potássio e do teor de água no solo, a difusão foi o principal mecanismo detransporte deK atéas raízes de milheto(Figura 1) concordando com os dados obtidos para mi lheto, soja, colza e lab-lab por Costa et al. (1988), e para outras culturas, tais como: o milho (Vargas et al., 1983; Barber, 1984; Becker \& Meurer, 1986), o arroz (Ruiz et al., 1999), o al godão (Rosolem et al., 2001) e otrigo (Marschner, 1995). 


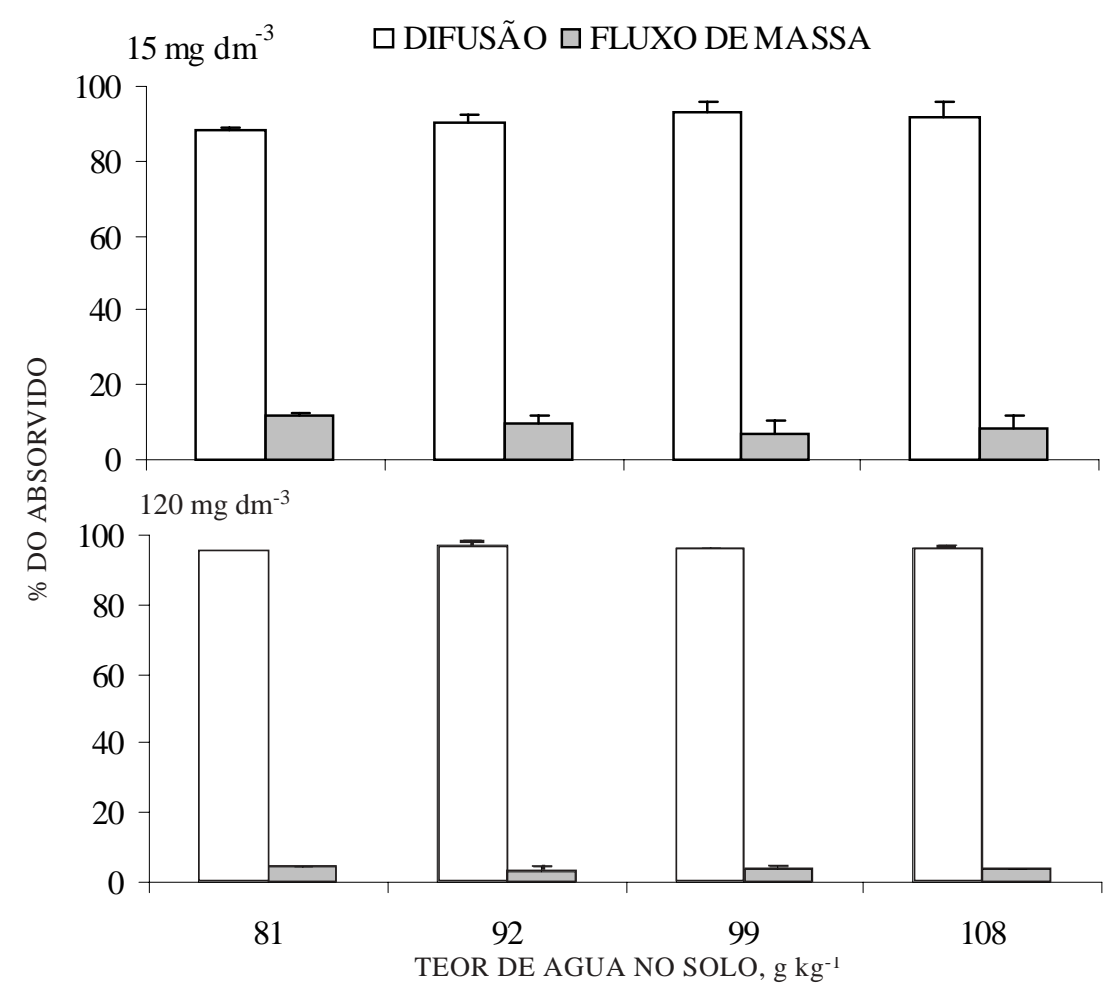

Figura 1. Contribuição relativa dos mecanismos de difusão e fluxo de massa no suprimento de potássio às raízes de mil heto (28 DAE), considerando os teores de água no solo, correspondentes aos potenciais testados, e as doses de potássio. As barras no topo das colunas representam o desvio-padrão da média.

Com a menor dose de potássio foi observada maior contribuição relativa do fluxo de massa, que chegou a $12 \%$ do $\mathrm{K}$ absorvido pelas plantas, contra $4 \%$ na maior dose do nutriente (F igura 1 ). O fluxo de massa, nas condições em que o teor de $K$ na solução do solo permanece el evado (145 mg L-1), como em um Latossolo Roxo utilizado por Becker \& Meurer (1986), contribuiu, no máximo, com 30,9\% do potássio total absorvido pelas plantas de milho. Ruiz et al. (1999), trabalhando com $\mathrm{K}_{2} \mathrm{CO}_{3}$ para correção do pH do solo, observaram que o fluxo de massa foi o principal mecanismo de suprimento de $\mathrm{K}$ às raízes do mil ho, decorrente da alta concentração de potássio na solução do solo (1.247 $\left.\mathrm{mg} \mathrm{L}^{-1}\right)$.

No presente trabalho, as concentrações de $K$ na sol ução do solo (Quadro 1) foram muito menores do que as observadas por Becker \& Meurer (1986) e Ruiz (1999), mas são compatíveis com os resultados obtidos por Vargas et al. (1983) que encontraram, na média de 12 solos do Rio Grande do Sul, teores de $8,6 \mathrm{mg} \mathrm{L}^{-1}$ deK na sol ução da camada superficial $\left(0-20 \mathrm{~cm}\right.$ ). A aplicação de $120 \mathrm{mg} \mathrm{dm}^{-3}$ de K (dose alta) proporcionou a concentração média de $14,9 \mathrm{mg} \mathrm{L}^{-1}$ na solução do solo (Quadro 1), teor considerado baixo, segundo Vargas et al. (1983), e responsável, em parte, pela baixa contribuição do fluxo de massa.

A alta concentração de Ca na solução do solo (Quadro 1) foi devida ao uso do cal cário para el evar a saturação por bases e ao uso de superfosfato simples como fonte de f'ósforo ( $20 \% \mathrm{Ca}$ ). I sso pode ter contribuído para os resultados observados. Rosolem et al. (2001) verificaram maior contribuição do fluxo de massa no suprimento de $K$ às raízes de algodão, quando não foi realizada a calagem, e na dose mais alta de $\mathrm{K}\left(60 \mathrm{mg} \mathrm{dm}^{-3}\right)$. A maior concentração de Ca eMg no solotambém podereduzir a atividade do íon $\mathrm{K}$ na solução do solo, reduzindo sua movimentação (Meurer \& Anghinoni, 2000).

A maior contribuição relativa do fluxo de massa com a menor dose de K pode ser explicada, uma vez que, enquanto a quantidade de $\mathrm{K}$ suprida às raízes por meio do fluxo de massa foi de 1,3 a 2,5 vezes maior (Figura 2), a quantidade suprida às raízes por difusão foi aproximadamente cinco vezes maior com a maior dose de potássio (Figura 3), para todos os teores de água estudados.

Outro fator que pode afetar a contribuição do fluxo de massa éa taxa transpiratória, que foi menor nos vasos com alto teor de potássio (Figura 4). Esse resultado está de acordo com aqueles relatados por Büll (1993), mostrando que plantas de milho bem supridas em potássio têm menor necessidade e menor perda de água, por causa da reduzida taxa de transpiração e da ação deste nutriente como agente osmótico no mecanismo de abertura e fechamento dos estômatos, o que resulta em maior eficiência do uso da água pelas plantas. 
Quadro 1. Concentração de potássio, cálcio e magnésio na solução do solo aos 15 e 25 DAE considerando os teores de água no solo, correspondentes aos potenciais testados, e as doses de potássio

\begin{tabular}{|c|c|c|c|c|c|c|}
\hline \multirow{4}{*}{$\begin{array}{c}\text { Teor } \\
\text { de água } \\
\text { no solo }\end{array}$} & \multicolumn{6}{|c|}{ Dose de $\mathrm{K}$ aplicada ao solo antes da semeadura $\left(\mathrm{kg} \mathrm{dm}^{-3}\right)$} \\
\hline & \multicolumn{3}{|c|}{15} & \multicolumn{3}{|c|}{120} \\
\hline & \multicolumn{2}{|c|}{ Data de amostragem } & \multirow{2}{*}{ Média } & \multicolumn{2}{|c|}{ Data de amostragem } & \multirow[b]{2}{*}{ Média } \\
\hline & 15 DAE* & 25 DAE & & 15 DAE & 25 DAE & \\
\hline \multirow[t]{2}{*}{$\mathrm{g} \mathrm{kg}^{-1}$} & \multicolumn{6}{|c|}{$-\mathrm{mg} \mathrm{L}^{-1}$} \\
\hline & \multicolumn{6}{|c|}{ Potássio } \\
\hline 81 & 8,9 & 10,2 & 9,6 & 24,5 & 9,4 & 17,0 \\
\hline 92 & 4,1 & 8,0 & 6,1 & 22,9 & 8,6 & 15,8 \\
\hline 99 & 4,1 & 5,1 & 4,6 & 28,0 & 6,6 & 17,3 \\
\hline 108 & 6,2 & 5,9 & 6,1 & 13,9 & 5,4 & 12,5 \\
\hline \multirow[t]{2}{*}{ Média } & 5,8 & 7,3 & 6,6 & 22,3 & 7,5 & 14,9 \\
\hline & \multicolumn{6}{|c|}{ Cálcio } \\
\hline 81 & 960 & 569 & 764 & 487 & 283 & 385 \\
\hline 92 & 539 & 320 & 430 & 742 & 390 & 566 \\
\hline 99 & 590 & 314 & 452 & 565 & 445 & 505 \\
\hline 108 & 578 & 338 & 458 & 401 & 275 & 338 \\
\hline \multirow[t]{2}{*}{ Média } & 667 & 385 & 526 & 549 & 348 & 448 \\
\hline & \multicolumn{6}{|c|}{ Magnésio } \\
\hline 81 & 265 & 67 & 166 & 117 & 54 & 85 \\
\hline 92 & 120 & 32 & 76 & 224 & 60 & 142 \\
\hline 99 & 135 & 37 & 86 & 165 & 117 & 141 \\
\hline 108 & 117 & 35 & 76 & 91 & 42 & 66 \\
\hline Média & 159 & 43 & 101 & 149 & 68 & 109 \\
\hline
\end{tabular}

DAE: Dias após a emergência.

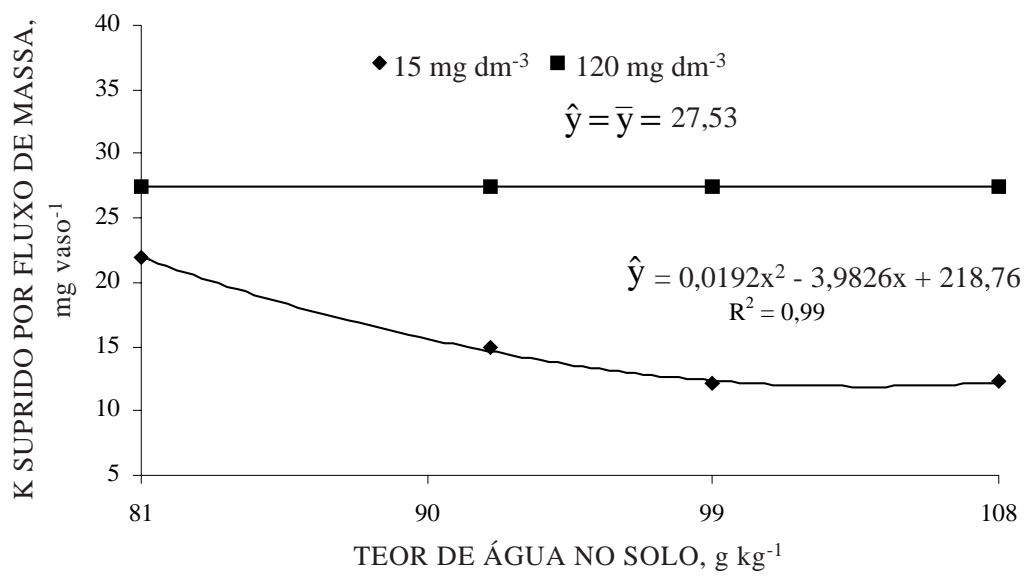

Figura 2. Quantidade de potássio suprida às raízes de mi l heto (28 DAE) por fluxo de massa, considerando os teores de água no solo, correspondentes aos potenciais testados, e as doses de potássio. Símbolos = valores observados; linha $=$ valores estimados.

Não houve efeito $(P<0,05)$ dos teores de água do solo nas quantidades de $K$ que entraram em contato com as raízes por difusão (Figura 2). Kuchenbuch et al. (1986) observaram que houve aumento da mobilidade do potássio por difusão no solo com aumento do conteúdo volumétrico de água de 0,1 para $0,4 \mathrm{~cm}^{3} \mathrm{~cm}^{-3}$, aumentando o coeficiente de difusão em dez vezes. Segundo os resultados 


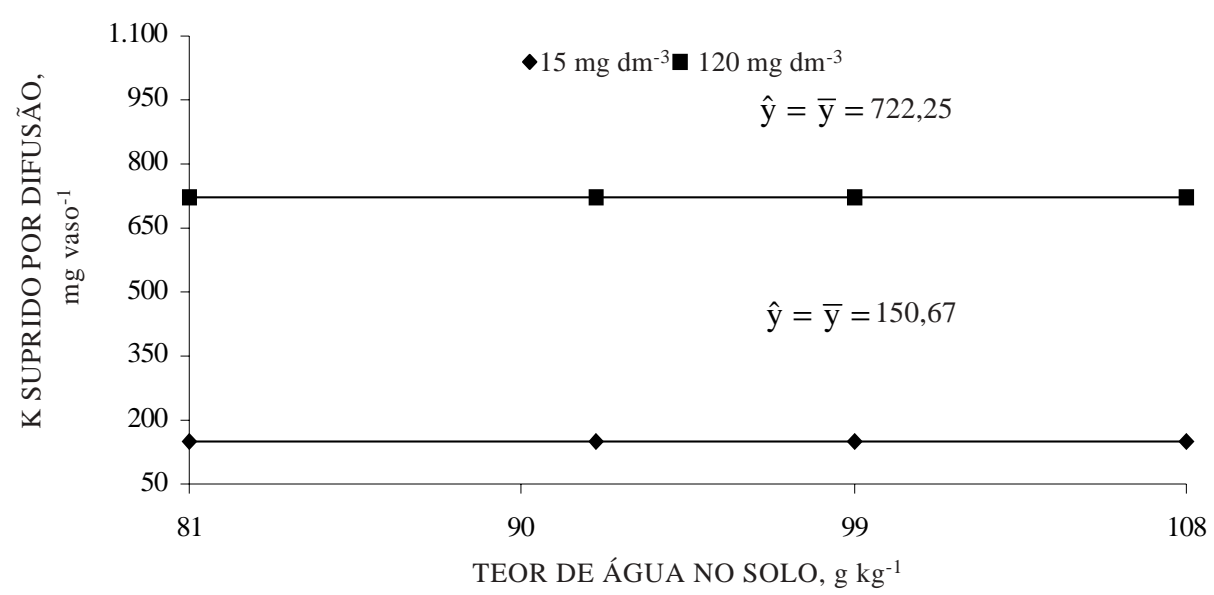

Figura 3. Quantidade de potássio suprida às raízes de milheto (28 DAE) por difusão, considerando os teores de água no solo, correspondentes aos potenciais testados, e a dose de potássio. Símbolos = valores observados; linha = valores estimados.

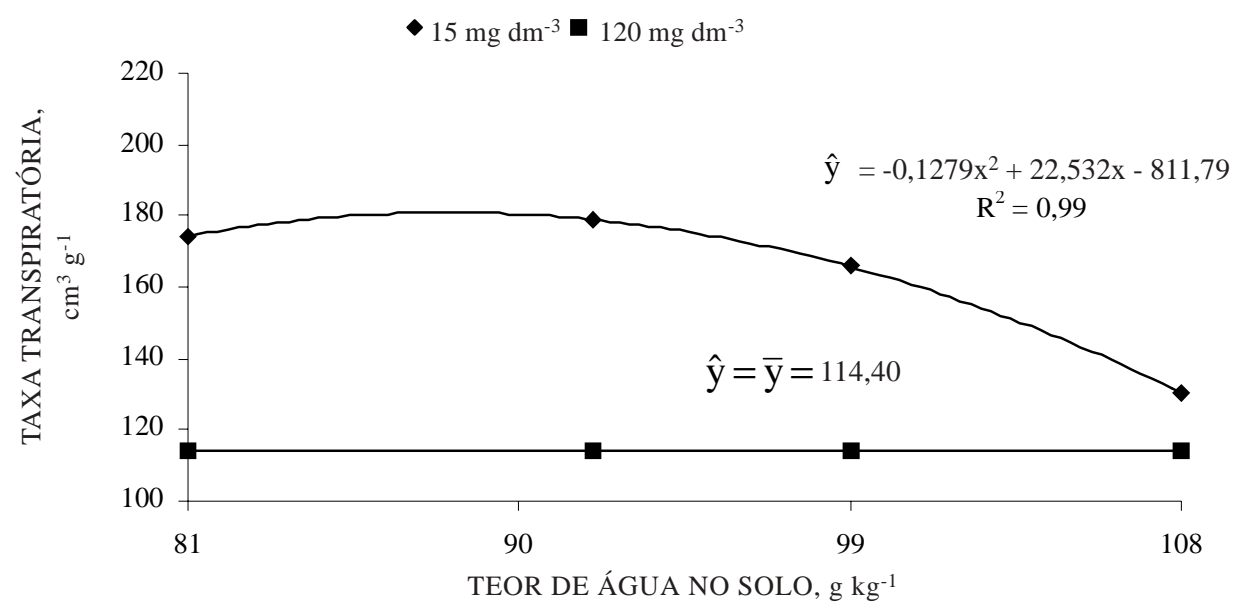

Figura 4. Taxa transpiratória do milheto (28 DAE), considerando os teores de água no solo, correspondentes aos potenciais testados, e as doses de potássio. Símbolos = valores observados; linha = valores estimados.

deste experimento, o menor teor de água já foi suficiente para neutralizar o efeito da tortuosidade do solo, não havendo diferenças significativas entre a quantidade de $\mathrm{K}$ suprida às raízes pela difusão nos diversos teores de água testados.

Os teores deágua utilizados não foram limitantes ao acúmulo de fitomassa na parte aérea do milheto nas duas doses de potássio aplicadas (Figura 5). A maior dose de potássio proporcionou maior acúmulo defitomassa na parte aérea, aproximadamente $24 \%$ maior que a menor dose, enquanto o maior teor de água no solo levou ao maior acúmulo de fitomassa seca nas raízes do milheto, independentemente das doses de potássio (Figura 5), tal como os resultados encontrados por Vilela \& Büll (1999), para o milho cultivado em três teores de água (sem estresse hídrico, estresse moderado e estresse intenso).
As maiores quantidades de potássio absorvidas foram encontradas nas plantas submeti das à maior dose de potássio (Quadro 2). A alta concentração de potássio na parte aérea dessas plantas (Figura 6) indica quea absorção de $\mathrm{K}$ foi superior à necessidade (absorção de luxo), uma vez que não houve diferença significativa na fitomassa acumulada na parte aérea (Figura 5), concordando com os resultados encontrados por Mackay \& Barber (1985), para a cultura do milho.

Como o acúmulo de fitomassa da parte aérea não foi influenciado pelos teores de água, a maior quantidade deK acumulado (Quadro 2) deveu-seao maior teor de $K$ na parte aérea e nas raízes (F igura 6), proporcionado pela maior concentração de potássio na solução de solo, e, portanto, à maior quantidade de potássio que entrou em contato com 

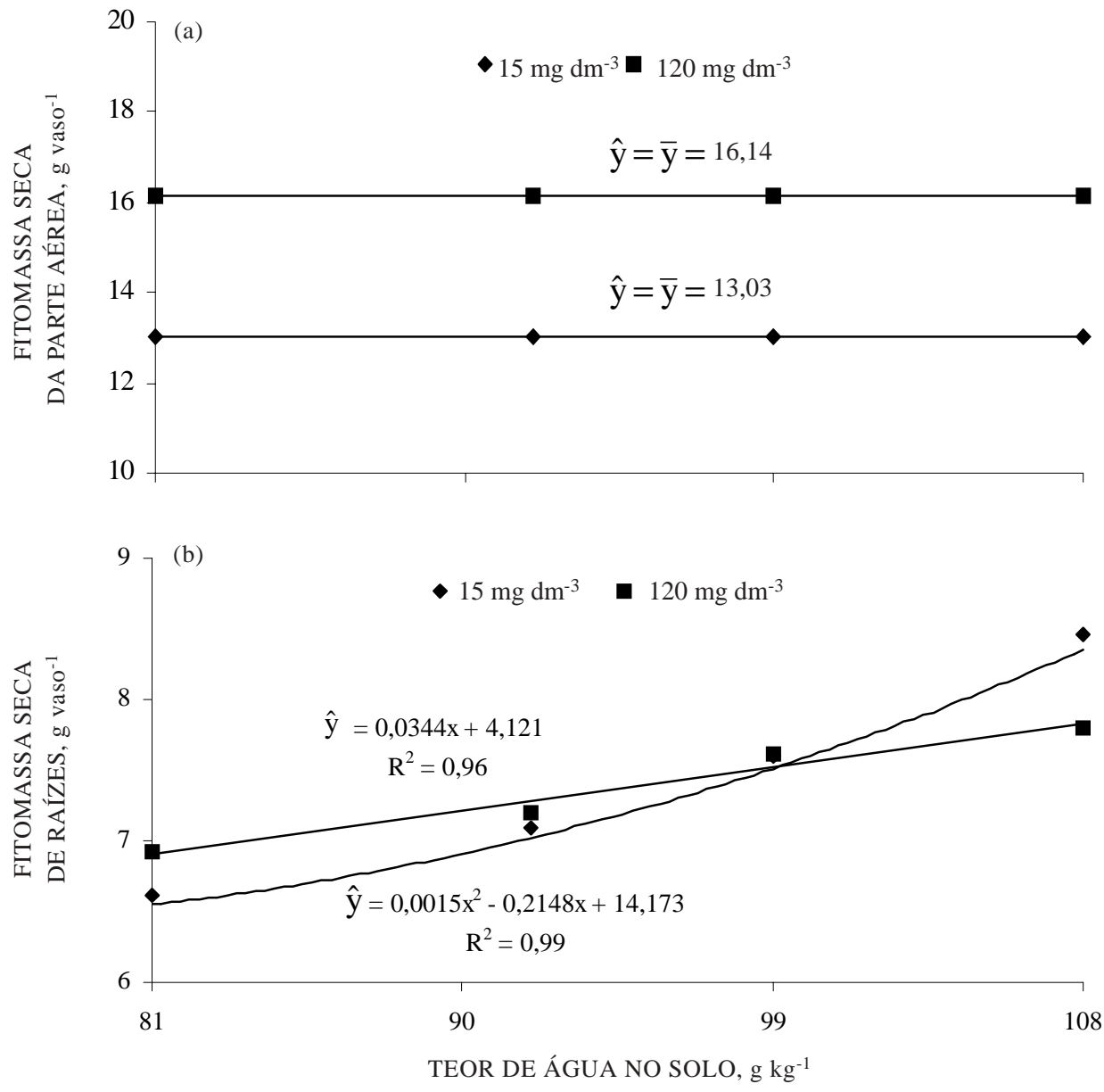

Figura 5. Acúmulo de fitomassa (a) na parte aérea e (b) nas raízes do mil heto (28 DAE ), considerando os teores de água no solo, correspondentes aos potenciais testados, e as doses de potássio. Símbolos = valores observados; linha = valores estimados.

Quadro 2. Quantidade de K acumulado nas raízes, na parte aérea e na planta, considerando as doses do nutriente

\begin{tabular}{cccc}
\hline \multirow{2}{*}{ Dose de K } & \multicolumn{3}{c}{ Acúmulo de potássio } \\
\cline { 2 - 4 } & Raiz & Parte aérea & Planta \\
\hline $\mathrm{mg} \mathrm{dm}^{-3}$ & $38 \mathrm{a}$ & $145 \mathrm{~b}$ & $183 \mathrm{~b}$ \\
15 & $86 \mathrm{~b}$ & $593 \mathrm{a}$ & $684 \mathrm{a}$ \\
120 & & &
\end{tabular}

Médias seguidas da mesma letra, na coluna, não diferem entre si pelo teste de Tukey a $5 \%$.

as raízes por difusão. Gianello e Mielniczuk (1981) observaram que a concentração de potássio na solução do solo foi o fator que mais influiu na absorção de potássio pelo milho.

Analisando os teores de água testados, não se observou diferença significativa na quantidade de potássio absorvida. No entanto, Seiffert et al. (1995) encontraram uma redução em cerca de $70 \%$ na absorção de potássio quando o conteúdo de água passou de 19 para $10 \mathrm{~cm}^{3} \mathrm{~cm}^{-3}$, como teoricamente esperado.

As características das raízes, como comprimento e diâmetro médio, não foram influenciadas pelos teores de água nas duas doses de K (Quadro 3). A área superficial das raízes foi maior na menor dose de potássio (Figura 7) e deveu-se, principal mente, à presença de raízes mais grossas, embora, nestecaso, a diferença nãotenha sido significativa (Quadro 3). Hallmark \& Barber (1981) relataram que esse aumento na área superficial da raiz de acordo com a menor disponibilidade de K pode ser um mecanismo de compensação da planta em solos mais pobres. Raízes mais finas apresentam geometria mais favorável para absorção de nutrientes cujo principal mecanismo de transporteéa difusão (Barber, 1984). Assim, raízes mais grossas, embora com superfície maior, favoreceriam otransporte por fluxo demassa, como ocorreu no presente trabalho. 

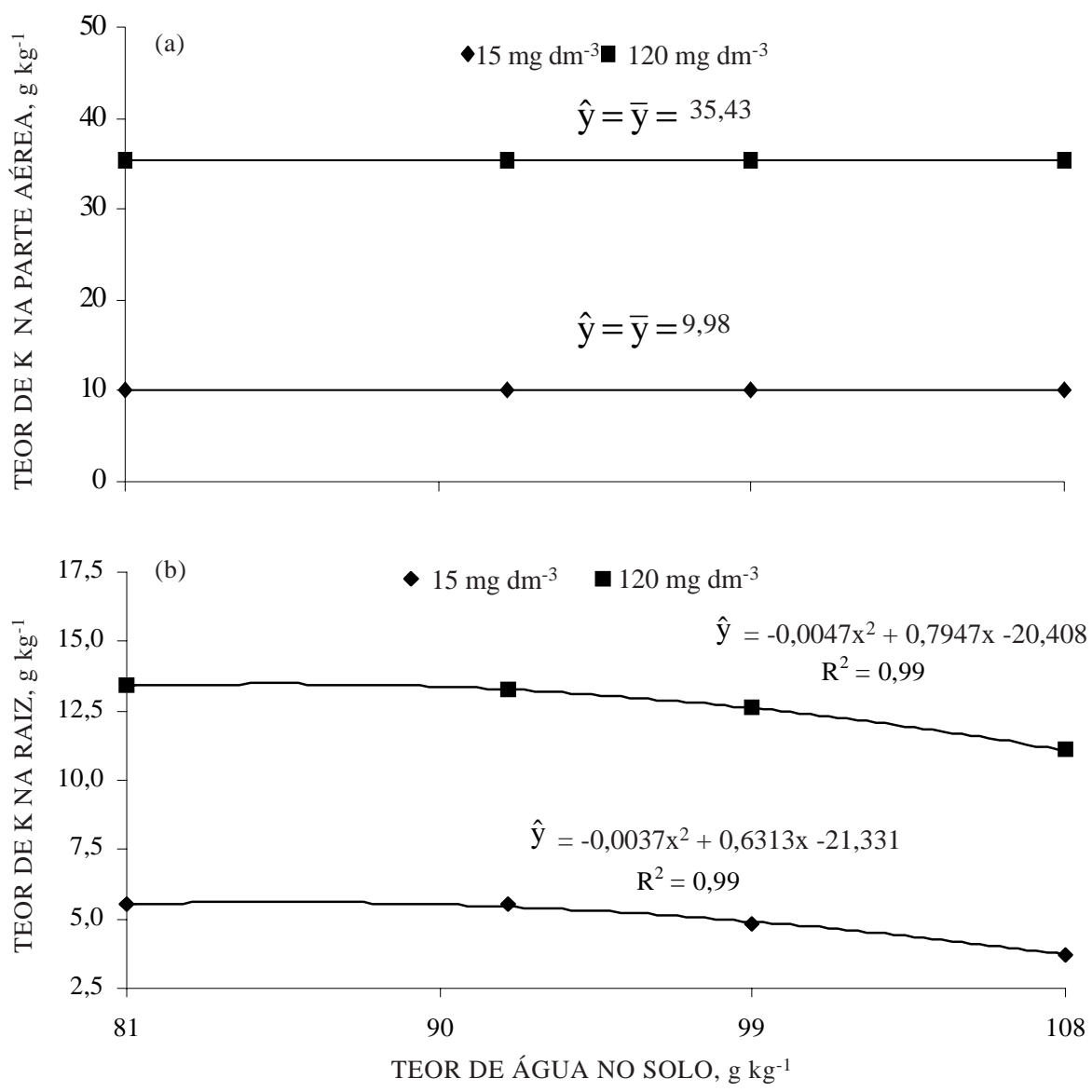

Figura 6. Teor de K (a) na parte aérea e (b) nas raízes do milheto (28 DAE), considerando os teores de água no solo, correspondentes aos potenciais testados, e as doses de potássio. Símbolos = valores observados; linha = valores esti mados.

Quadro 3. Comprimento total, diâmetro médio e volume total das raízes de mil heto considerando os teores de água no solo, correspondentes aos potenciais testados, e as doses de potássio

\begin{tabular}{|c|c|c|c|c|c|c|c|c|c|}
\hline \multirow{3}{*}{$\begin{array}{l}\text { Teor de água } \\
\text { no solo }\end{array}$} & \multicolumn{9}{|c|}{ Dose de K (mg dm-3) } \\
\hline & 15 & 120 & \multirow{2}{*}{ Média } & 15 & 120 & \multirow{2}{*}{ Média } & 15 & 120 & \multirow{2}{*}{ Média } \\
\hline & \multicolumn{2}{|c|}{ Comprimento total } & & \multicolumn{2}{|c|}{$\overline{\text { Diâmetro médio }}$} & & \multicolumn{2}{|c|}{ Volume total } & \\
\hline $\mathrm{g} \mathrm{kg}^{-1}$ & 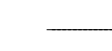 & n vaso-1 & - & 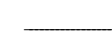 & $-\mathrm{cm}$ & - & 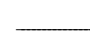 & $-\mathrm{cm}^{3}-$ & - \\
\hline 108 & 113 & 115 & 114 & 0,040 & 0,040 & 0,040 & 174 & 116 & 145 \\
\hline 99 & 131 & 102 & 116 & 0,042 & 0,039 & 0,041 & 179 & 93 & 136 \\
\hline 92 & 103 & 94 & 99 & 0,044 & 0,041 & 0,042 & 175 & 140 & 158 \\
\hline 81 & 106 & 95 & 101 & 0,043 & 0,041 & 0,042 & 203 & 132 & 167 \\
\hline \multirow[t]{2}{*}{ Média } & 113 & 102 & & 0,042 & 0,040 & & $183 a$ & $120 \mathrm{~b}$ & \\
\hline & \multicolumn{9}{|c|}{ Resumo dos resultados da análise de variância } \\
\hline $\begin{array}{l}\mathrm{K} \\
\mathrm{H}_{2} \mathrm{O} \\
\mathrm{K} \times \mathrm{H}_{2} \mathrm{O}\end{array}$ & & $\begin{array}{l}\text { NS(1) } \\
\text { NS } \\
\text { NS }\end{array}$ & & & $\begin{array}{l}\text { NS } \\
\text { NS } \\
\text { NS }\end{array}$ & & & $\begin{array}{l}0,01 \\
\text { NS } \\
\text { NS }\end{array}$ & \\
\hline C.V. (\%) & & 27,76 & & & 7,55 & & & 45,82 & \\
\hline
\end{tabular}

${ }^{(1)}$ NS: não-significativo $(P<0,05) .{ }^{(2)}$ Nível de significância do teste $F$. 


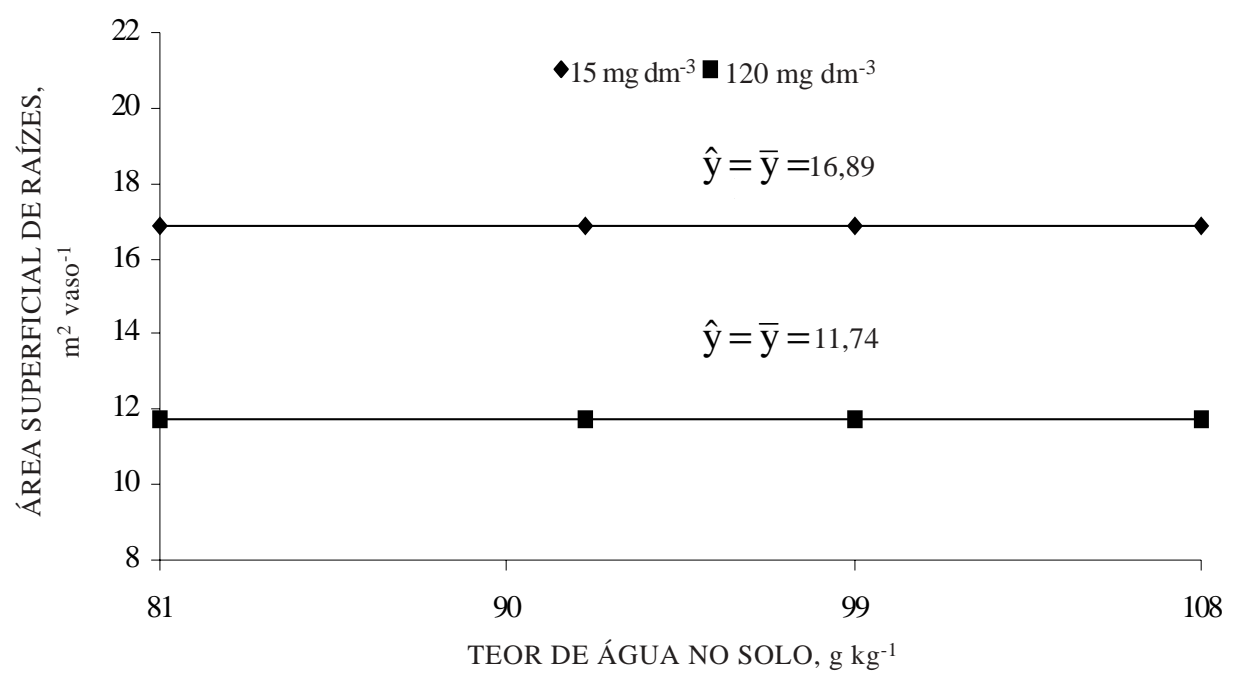

Figura 7. Área superficial das raízes do milheto (28 DAE), considerando os teores de água no solo, correspondentes aos potenciais testados, e as doses de potássio. Símbolos = valores observados; linha $=$ valores estimados.

\section{CONCLUSÕES}

1. A baixa disponibilidadedepotássioproporcionou maior superfície radicular ao milheto.

2. Independentementeda dose de potássioedoteor deágua no solo, a difusão foi o principal mecanismo de transporte de $\mathrm{K}$ no solo.

3. O fluxo de massa chegou a contribuir com $12 \%$ do $\mathrm{K}$ absorvido pelas plantas cultivadas em baixa disponibilidade do nutriente, contra apenas $4 \% \mathrm{em}$ solos com maior disponibilidade de K.

4. A água do solo, desde que não tenha sido limitante ao crescimento da planta, não interferiu nos mecanismos de transporte de $\mathrm{K}$ no solo.

\section{LITE RATURA CITADA}

BARBER, S.A. Soil nutrient bioavaliability: A mechanistic approach. New York, J ohn Willey, 1984. 397p.

BECKER, M. \& MEURER, E.J . Morfologia deraízes, suprimento e influxo de potássio em plantas de milho. R. Bras. Ci. Solo, 10:259-263, 1986.

BÜLL, L.T. Nutrição mineral do milho. In: BÜLL, L.T. \& CANTARELLA, H., eds. Cultura do milho: Fatores que afetama produtividade. Piracicaba, POTAFOS, 1993. p.63-131.

COSTA, N.L.; SI LVA FI LHO, G.N.; SENA, J .O.A.; RODRIGUES, A.N.A. \& ANGHINONI, I. Mecanismos de suprimento e eficiência de absorção de potássio em soja, milho, milheto, colza e lab-lab. Pesq. Agropec. Bras., 23:463-468, 1988.
EMPRESA BRASILEIRA DE PESQUISA AGROPECUÁRIA EMBRAPA. Centro de pesquisa Agropecuária do Oeste (Dourados, MS). Milho: informações técnicas. Dourados, 1997, 222p. (EMBRAPA-CPAO, Circular técnica, 5)

EMPRESA BRASILEIRA DE PESQUISA AGROPECUÁRIA EMBRAPA. Centro de pesquisa de solos (Rio de J aneiro, RJ ). Sistema Brasileiro de Classificação de Solos. Rio de J aneiro, 1999. 412p.

GIANELLO, C. \& MIELNICZUK, J . Características químicas e físicas do sol o que afetam a absorção do potássio por plantas de milho. R. Bras. Ci. Solo, 5:109-114, 1981.

GRIMME, H. Development of K-fertilizer recommendation. In: COLLOQUIUM OF THE INTERNATIONAL POTASH INSTITUTE, 22., Soligork, 1990. Proceedings. Soligok, IPI, 1990. p.117-131.

HALLMARK, W.B. \& BARBER, S.A. Root growth and morphology, nutrient uptake, and nutrient status of soybean as affected by soil K and bulk density. Agron. J., 73:779-782, 1981.

KLEPKER, D. \& ANGHINONI, I. Características físicas e químicas do solo afetadas por métodos de preparo e modos de adubação. R. Bras. Ci. Solo, 19:395-401, 1995.

KUCHENBUCH, R.; CLAASSEN, N. \& J UNCK, A. Potassium availability in relation to soil moisture. I. Effect of soil moisture on potassium diffusion, root growth and potassium uptake of onion plants. Plant Soil, 95:221-231, 1986.

MACKAY, A.D. \& BARBER, S.A. Soil moisture effect on potassium uptake by corn. Agron. J ., 77:524-527, 1985.

MALAVOLTA, E.; VITTI, G.C. \& OLIVEIRA, S.A. Avaliação do estado nutricional das plantas: princípios e aplicações. 2.ed. Piracicaba, POTAFOS, 1997. 317p.

MARSCHNER, H. Mineral nutrition of higher plants. 2.ed. London, Academic Press, 1995. 889p. 
MEURER, E.J. \& ANGHINONI, I. A solução do solo. In: MEURER, E.J ., ed. Fundamentos de química de solo. Porto Alegre, Genesis, 2000. p.63-76.

RAIJ , B. van \& QUAGGIO, J .A. Métodos de análises de solo para fins de fertilidade. Campinas, Instituto Agronômico de Campinas, 1983. 31p. (Boletim Técnico, 81)

RICHARDS, L.A. Methods of measuring soil moisture tension. Soil Sci., 68:95-112, 1949.

ROSOLEM, C.A.; ESTEVES, J .A.F. \& SILVA, R.H. Significance of mass flow and diffusion in supplying $K$ to cotton roots as affected by liming and $K$ rates. In: INTERNATIONAL SYMPOSIUM ON PLANT-SOIL INTERACTIONS AT LOW pH, 5., South Africa, 2001. Programme. África do Sul, 2001. p.48

RUIZ, H.A.; MIRANDA, J . \& CONCEIÇÃO, J.C.S. Contribuição dos mecanismos de fluxo de massa e de difusão para o suprimento de $\mathrm{K}$, Ca e Mg a plantas de arroz. R. Bras. Ci. Solo, 23:1015-1018, 1999.
SALTON, J.C. \& HERNANI, L.C. Cultivos de primavera: alternativa para produção de pal ha no Mato Grosso do Sul. In: REUNIÃO BRASILEIRA DE MANEJO E CONSERVAÇÃO DO SOLO, 10., Florianópolis, 1994. Resumos. Florianópolis, SOCIEDADE BRASILEIRA DE CIÊNCIA DO SOLO, 1994. p.248-249.

SEIFFERT, S.; KASELOWSKY, J .; J UNGK, A. \& CLAASSEN, $\mathrm{N}$. Observed and calculated potassium uptake by maize as affected by soil water content and bulk density. Agron. J ., 87:1070-1077, 1995

VARGAS, R.M.B.; MEURER, E.J.\& ANGHINONI, I. Mecanismos de suprimento de fósforo, potássio, cálcio e magnésio às raízes de milho em solos do Rio Grande do Sul. R. Bras. Ci. Solo, 7:143-148, 1983.

VILELA, E.F. \& BÜLL, L.T. Avaliação do crescimento de plantas de milho em função de doses de potássio e estresse hídrico. R. Bras. Ci. Solo, 23:281-289, 1999. 